\title{
MAGNETIC PROPERTIES OF THE H-10 MAGNET
}

\section{AD \\ BOOSTER TECHNICAL NOTE \\ NO. 148}

E. RODGER and V. BADEA

SEPTEMBER 29, 1989

ACCELERATOR DEVELOPMENT DEPARTMENT BROOKHAVEN NATIONAL LABORATORY UPTON, NEW YORK 11973 
During the months of July and August 1989 H-10 magnet experiments were set up with the following goals in mind:

1. Determine the configuration of magnet and circulating beam pipe which results in the lowest stray field;

2. Determine (as above) the most uniform field inside of the aperture;

3. Determine the main field response in and out of the aperture tube.

The setup had 14 configurations as shown in Fig. 1 .

A few photographs were selected to illustrate the actual setup, the way it was built in the field, and are shown in Figs. $2,3,4,5$, and 6 .

Figure 2 shows the \#1 configuration (see Fig. 1) (H-10 magnet without the aperture tube and no circulating beam pipe.)

Figure 3 represents the \#3 configuration which is similar to \#5 and \#II (see Fig. 1) which have the aperture tube mounted in and the carbon steel pipe attached for the circulating beam.

Figure 4 shows the \#4 configuration (see Fig. 1) which has the aperture tube shorted at both ends to the stainless steel circulating beam pipe.

Figure 5 presents the setup for \#9 (see Fig. 1) which is the H-10 Mark IV.

Figure 6 shows the setup for \#13 (see Fig. 1).

A short version of the $\mathrm{H}-10$ was used (26" long) for configurations \#1, \#2, \#3, \#4, \#5, \#5B, \#6, \#7, \#8, \#10, \#11, and \#12. For Configuration \#9 a spare H-10 Mark IV magnet was used, which was previously mounted in the ring. For Configuration \#13, a H-10 Mark V magnet was used. To measure the field a Gaussmeter (hall probe), model STGI-0402, made by F.W. Bell was used; the probe had a linearity of $1 \%$ of reading to $10 \mathrm{~K}$ Gauss. The power supply of the probe had a noise filter on the circuit. To attain the repeatability of probe location, a X - Y Table with an accuracy of .001" was used. (See Fig. 7.) The measurements were taken at 1" longitudinally inside of lamination stack in six different points as per Fig. 8 . 
For each configuration, at least twelve measurements were taken: Six with power on, and six with power off. Additional readings were taken to establish repeatability. A digital oscilloscope was used to record the current and the magnetic field; the pictures of curves were taken (cca 200) and were enlarged and composed. The repeatability was cca 1\%. The error margin coming from composing the curves, enlarging the scale, and other unknown factors was approximated at $4 \%$.

Results

The results were summarized in Figs. 9 and 11 , which show the field measured at the peak, (expressed in Gauss) and the time delay between the peak of the current and the peak of the field (expressed in microseconds). The location of measuring points was shown in Fig. 8 .

The graphs of Fig. 10 show the variation of the main field and stray field. The location of measuring points (time delay) was the same as above.

The graphs of Fig. 12 show the variation of the response time at measuring points.

Using the results shown in Figs. 9, 10, 11, and 12, the following conclusion can be drawn:

A. The highest stray field was observed at configurations: (for number specification see Fig. 9).

- 6 = with carbon steel circulating beam pipe with electric short between the pipe and the aperture tube;

-7 = with stainless steel circulating beam pipe with electric short between the pipe and the aperture tube;

- $13=\mathrm{H}-10$ Mark $\mathrm{V}$ (which is also shorted between the aperture and beam pipe).

B. The lowest stray field happened to be for the following configurations:

- 11 = the carbon steel circulating beam pipe with no vertical play between septum and lamination; 
- 5 = the carbon steel circulating beam pipe with a vertical play of .066" between septum and lamination and a .027 mylar shield between the circulating pipe and septum magnet face surface.

- 3 = carbon steel circulating beam pipe with a vertical play of .066" between septum and lamination.

c. The highest and most uniform main field was attained at configurations:

- $9=\mathrm{H}-10$ Mark IV;

-2 = no circulating beam pipe or aperture tube.

- 5 = carbon steel circulating beam with a vertical play of .066" between septum and lamination;

$-4=$ stainless steel circulating beam pipe and .066" play between septum and lamination.

D. The lowest main field was attained at configurations:

- 6 = carbon steel circulating beam pipe and tube inside of aperture with electrical short at both ends of circulating beam pipe and tube;

- 7 = stainless steel for circulating beam and the short the same as above;

$-13=\mathrm{H}-10$ Mark V.

E. The fastest and most uniform time response was given by the following configurations:

- $11=$ the carbon steel circulating beam pipe with no vertical play between the septum and lamination;

- $10=$ the stainless steel circulating beam pipe with no vertical play between the septum and lamination; 
Recommendations

A. An electrical break to be mounted between the end flanges and the aperture tube (to eliminate the electrical short).

B. The septum to be fitted into the lamination with a gap of maximum .006". (Using a layer of .003" kapton on top and bottom of copper bar, the septum will present a "locational fit" - no actual play.)

c. A layer of non-magnetic spacer (mylar or kapton of .027" thk) may be used to increase the gap between the septum-magnet face surface and the circulating beam pipe, and consequently, reduce the stray field.

D. The circulating beam pipe to be made of carbon steel.

E. One has to further investigate the \#11 Configuration (carbon steel circulating beam pipe and stainless steel aperture tube), to find out the variation of the magnetic field along the whole length of magnet. (The hall probe gives results just at certain locations as shown above).

Final Conclusions

1. The electrical short brings a variation of the main field between $4.25 \%$ to $10 \%$. (See configurations \#6, \#7, and \#13).

2. The electrical short generates a very high stray field, up to $10 \%$ of the main field $\approx 1000$ Gauss (see configurations \#6, \#7, and \#13).

3. When the short is not present, the variations of main field inside of aperture are on the order of $2.5 \%$ and stray field is reduced by one order of magnitude.

4. The most uniform field inside the aperture tube turns out to be for configurations \#2, \#5, \#9, and \#11.

5. By using the carbon steel pipe for the circulating beam and the stainless steel tube for the aperture, the stray field was reduced by $50 \%$; the pumping down time and the outgassing phenomenon were scaled down also, but the uniformity of the magnetic field inside of aperture was disturbed. The field variation for $\mathrm{H}-10$ Mark $\mathrm{V}$ was $1.01 \%$ (configuration \#9) 
versus $2.54 \%$ for configuration \#11 (see Fig. 3). (See "E" above). As previously stated, the repeatability of these measurements is approximately $1 \%$. Therefore, further measurement of the aperture field uniformity are probably required if variations on this order would be a problem either in the $\mathrm{H}-10$, booster injector, or AGS injector septum magnets. 
(1) NQ APERTURE TUBE

(2) WITH APERTURE TUBE $\square$

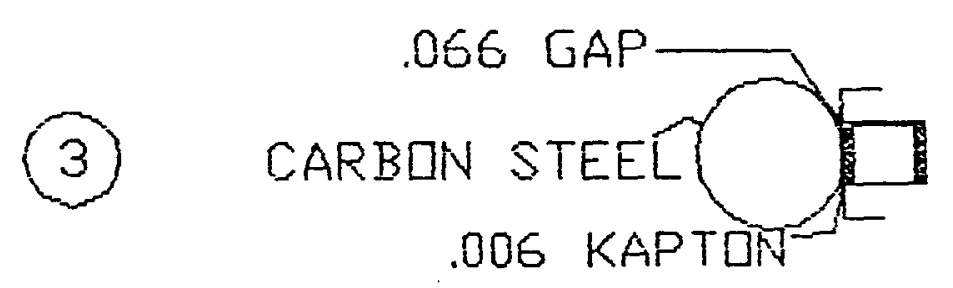

(4) STAINLESS STEELT 066 GAP

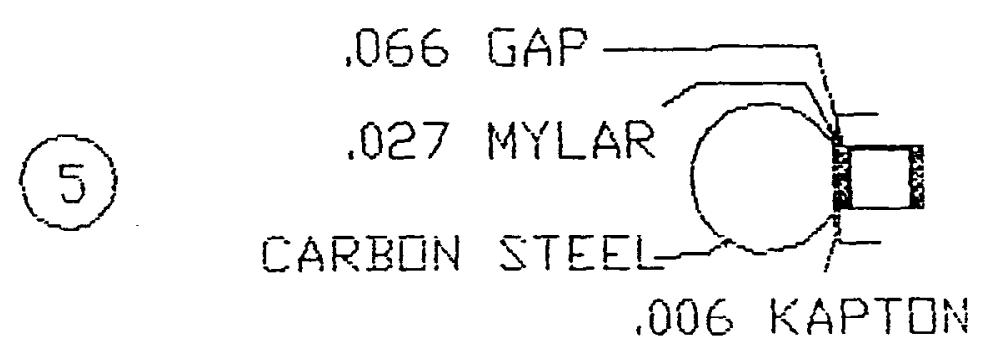

Fig 1: Experiment configurations. 
(5B)

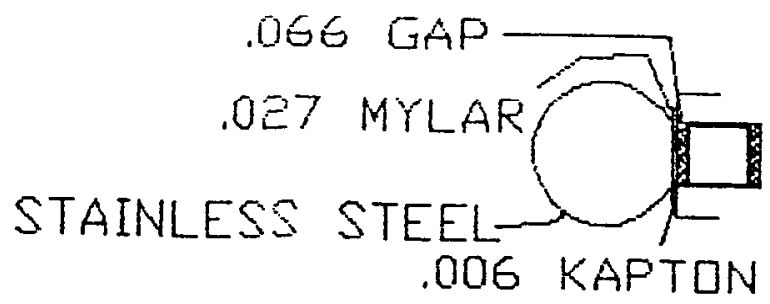

(6)

.066 GAP

CARBON STEE

.006 KAPTON

(7) .066 GAP-

STAINLESS STEEL SHORT BETW: LFARGE TUBE

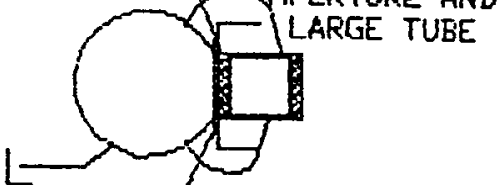
.006 KAPTON .066 GAF- COPPER SHIELD
16.006 KAPTON-

(8)

(9) I HHERT. AFEETURE TUFE SEGMENTS

Fig 1: Experiment configurations ( cont) . 

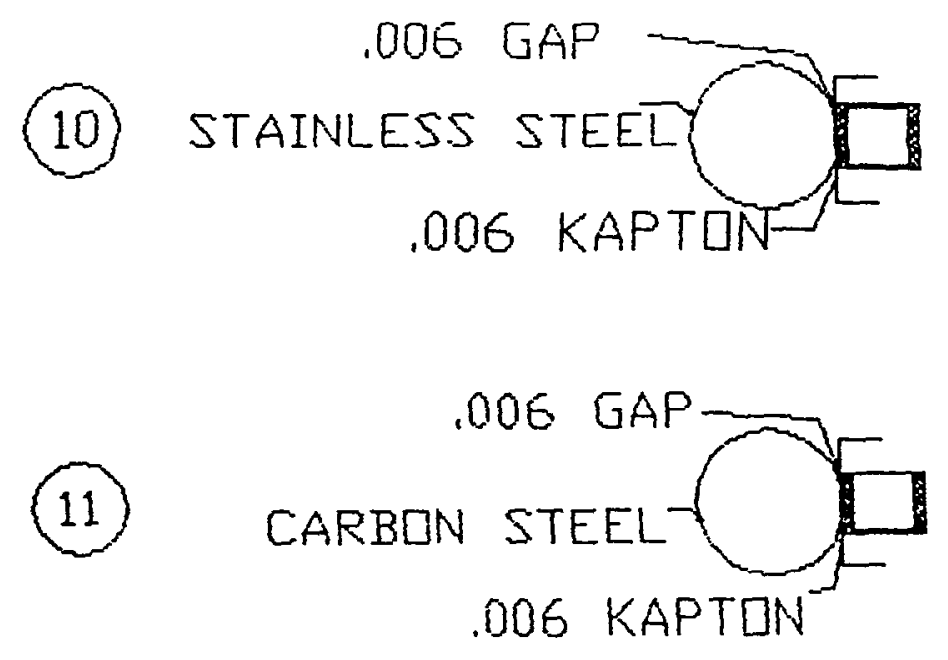

(15)

.006 GAP

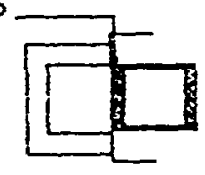

(13) H-10 MARK $V$

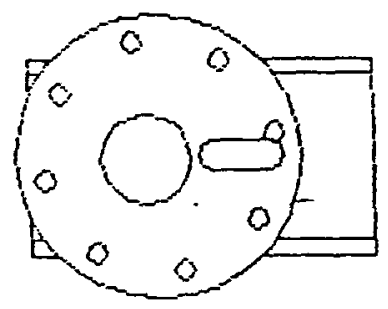

Fig 1: Experiment configurations ( cont). 


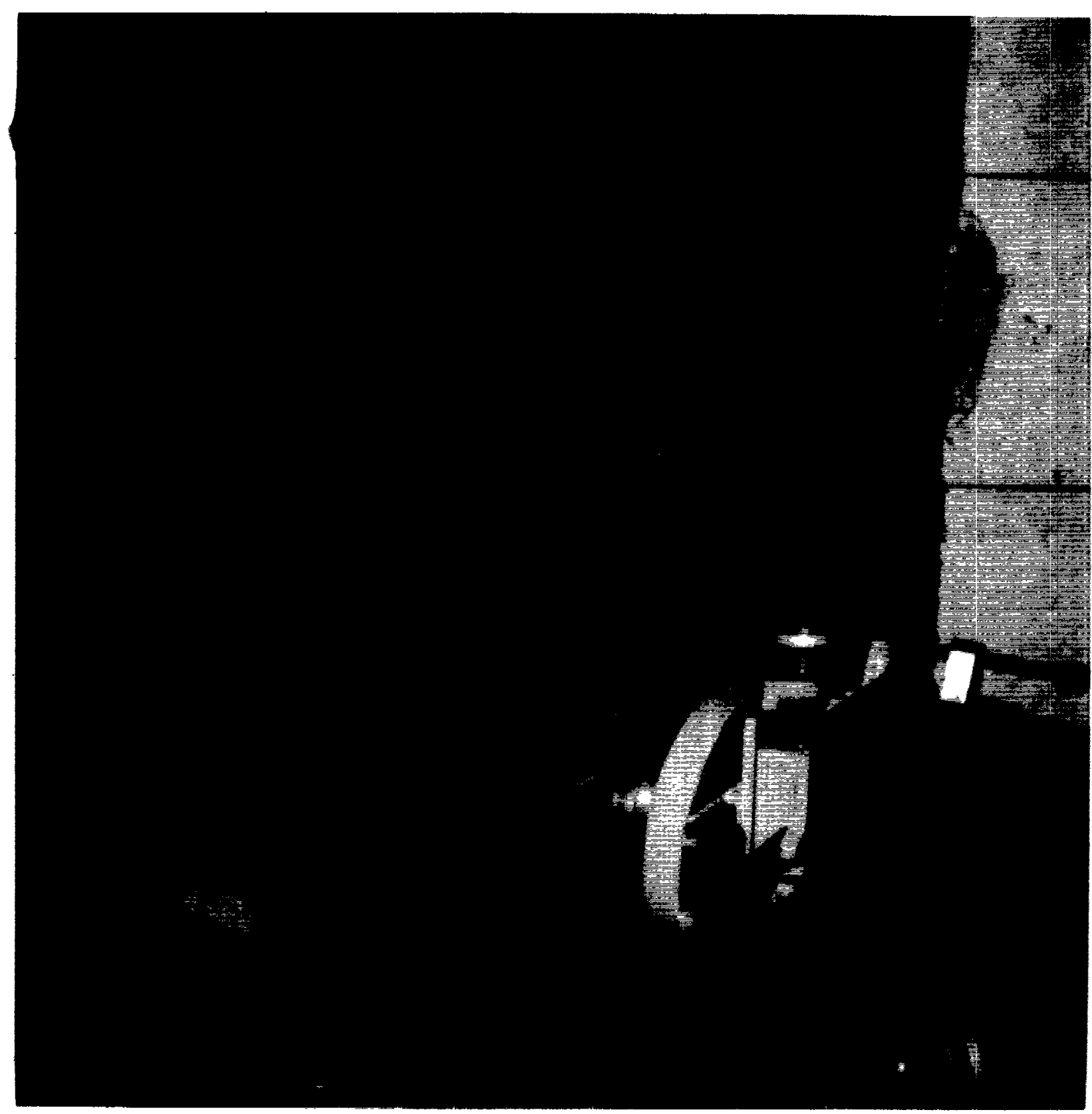

Fig 2: B-10 Magnet without aperture tube and without circulating beam pipe. ( Setup no. 1 ) 


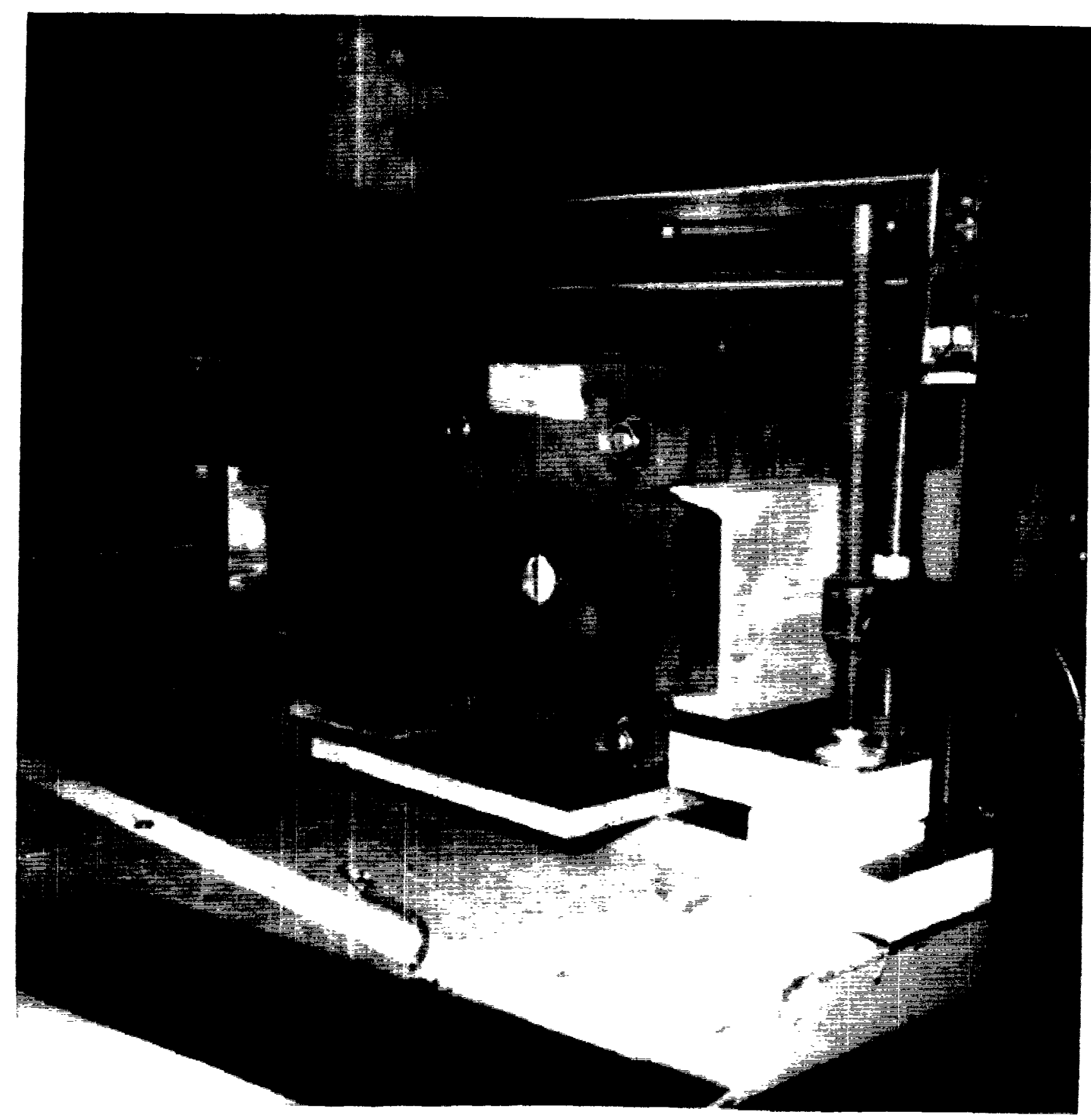

Fig 3: H-10 Magnet with aperture tube mounted and the carbon steel pipe attatched for the circulating beam. ( Setup no. 3, 5, and 11 ) 


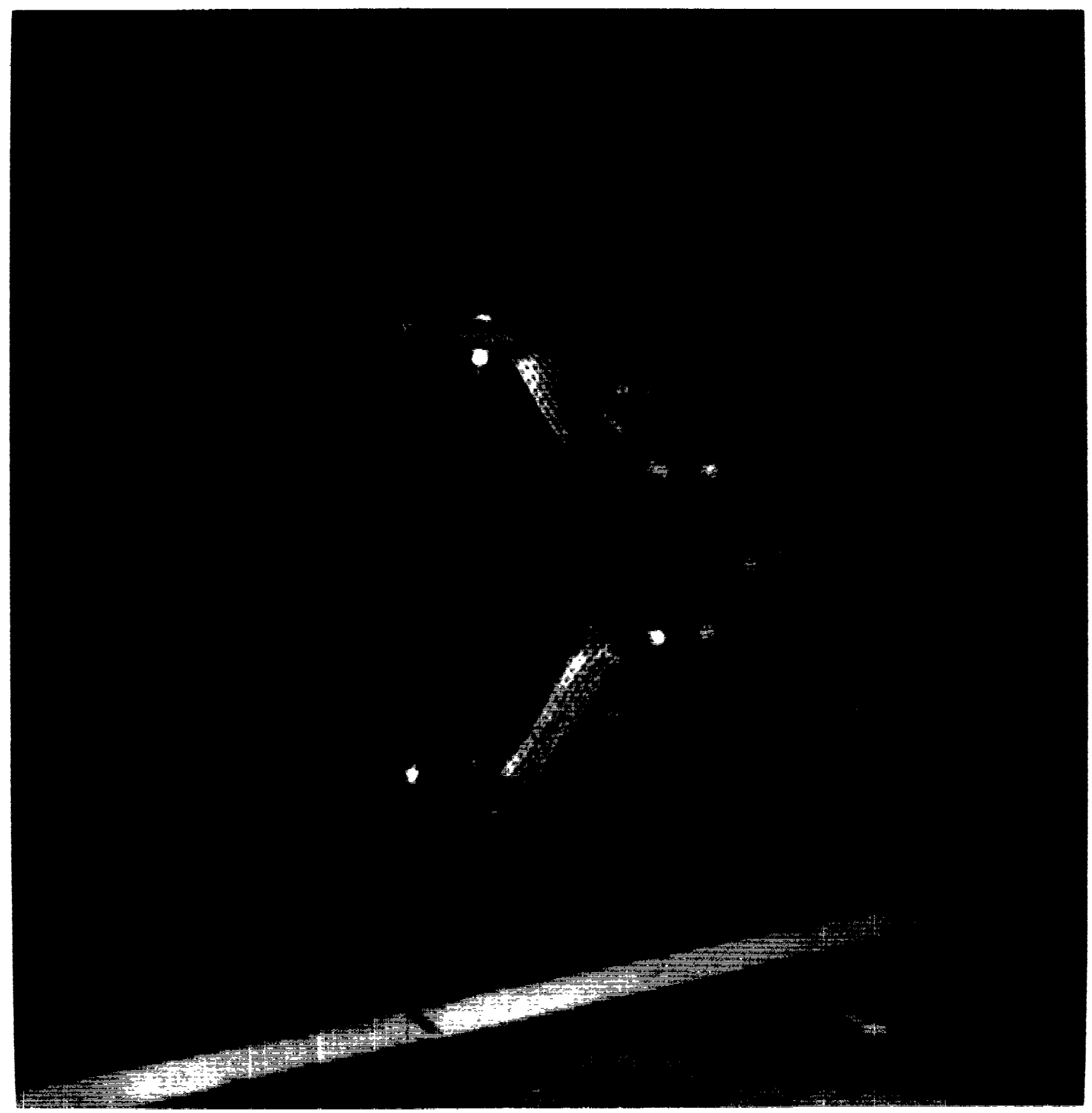

Fig 4: B-10 magnet with aperture tube mounted and the stainless steel pipe attached for the circulating beam. Electrical short at both ends. ( Setup no. 4 ) 


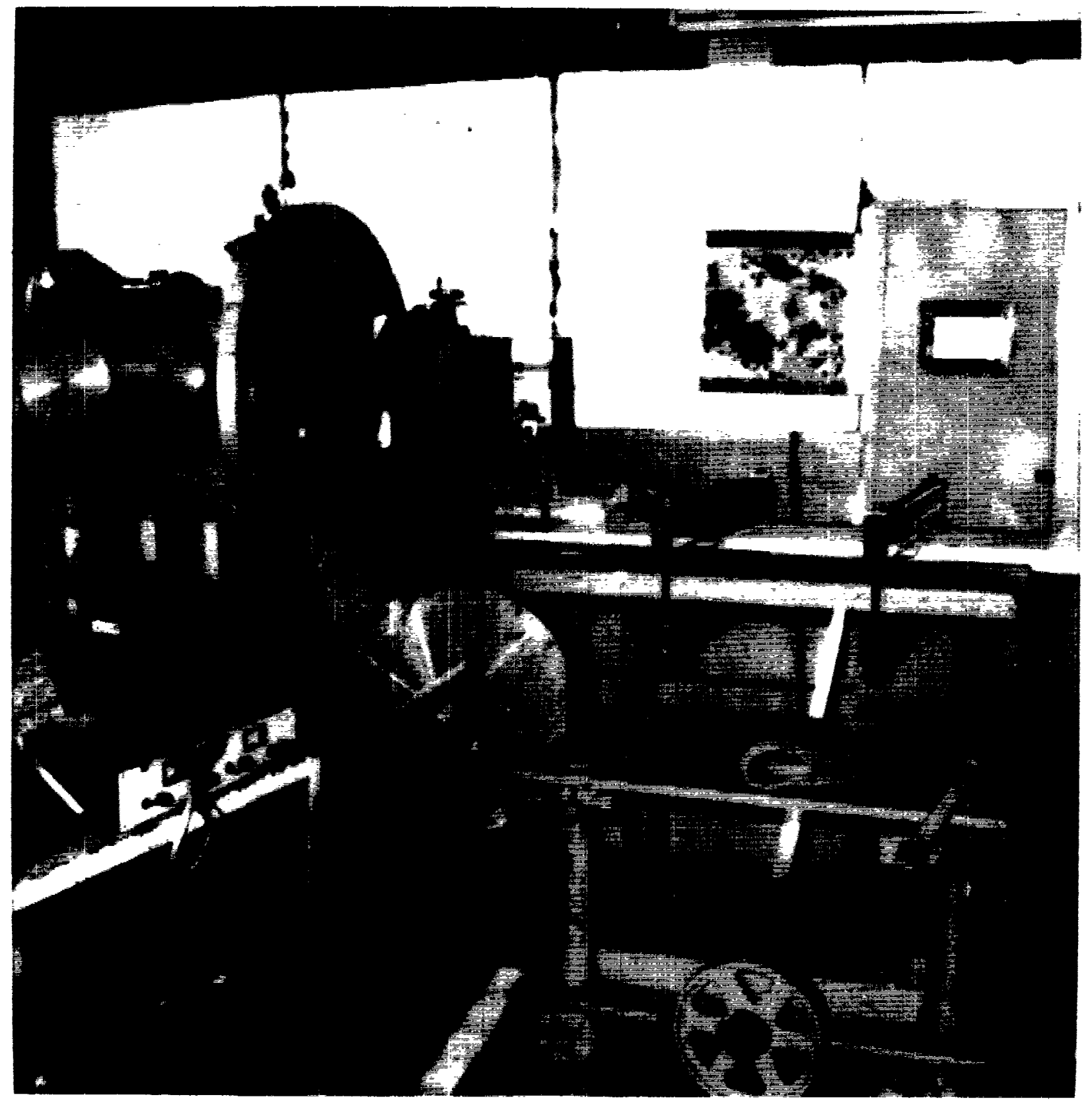

Fig 5: H-10 MARK IV ( Setup no. 9) 


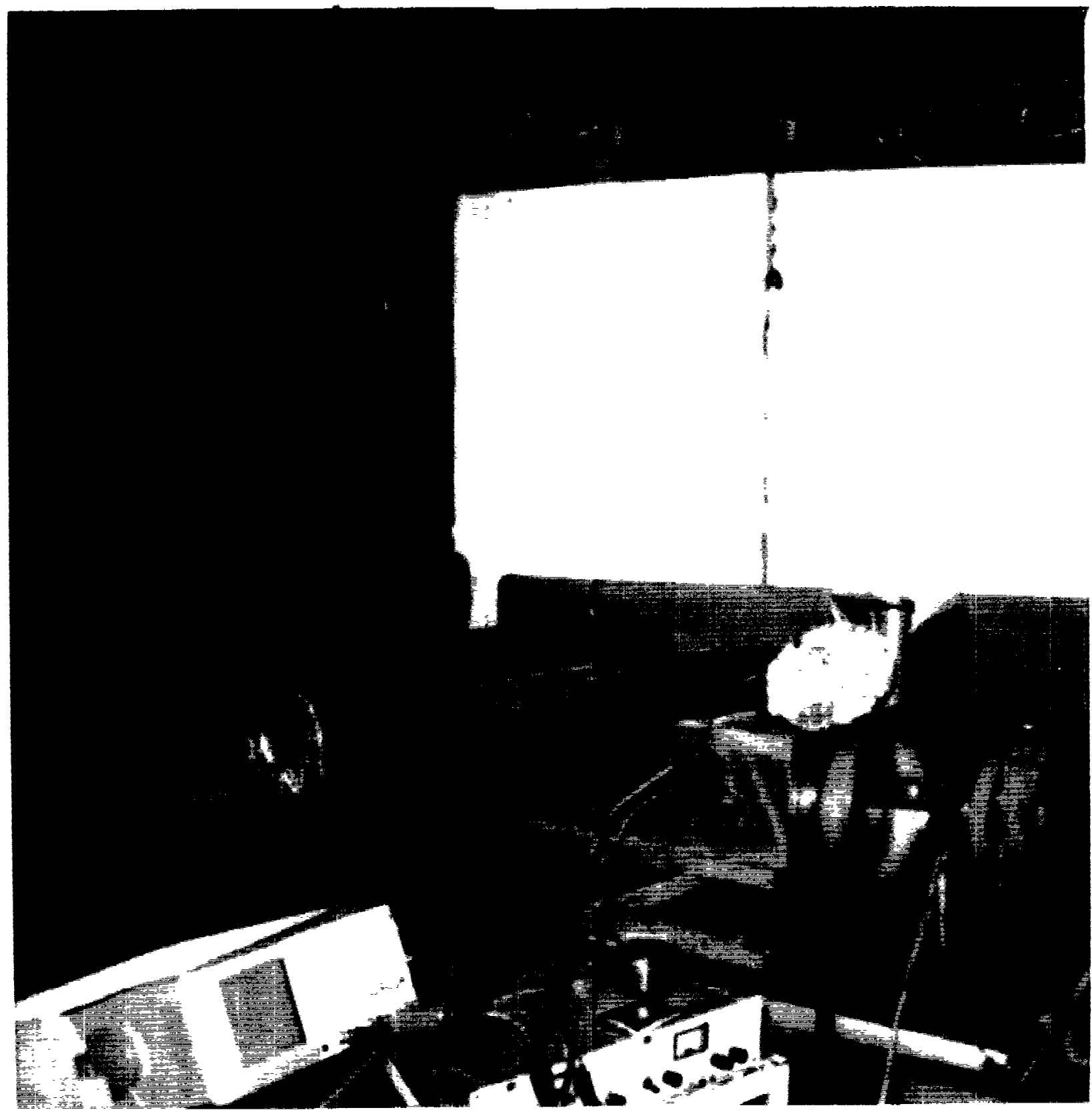

Fig 6: B-10 MARK V ( Setup no. 13) 


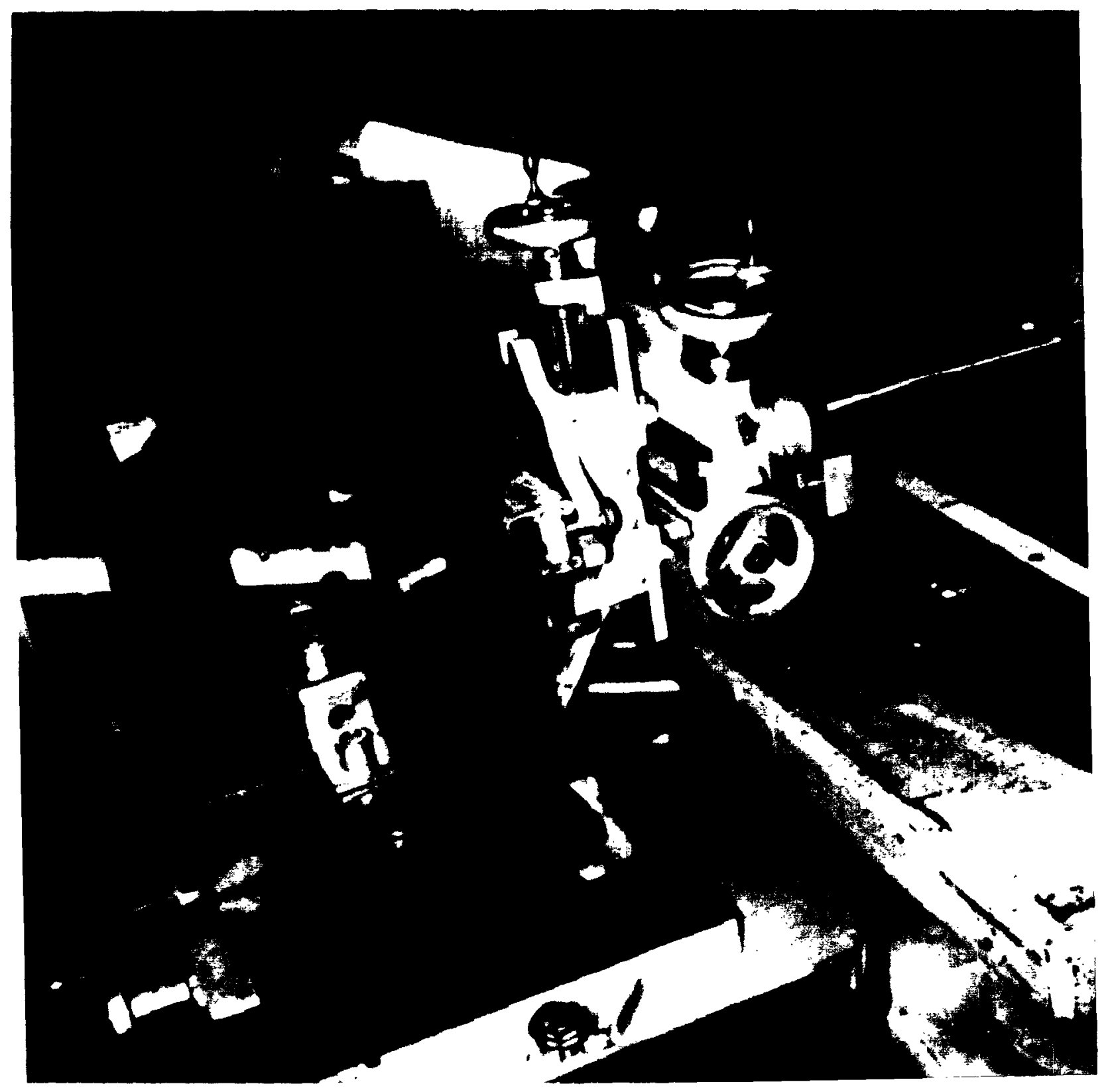

Fig 7: X-Y-Z table, .001 accuracy. 


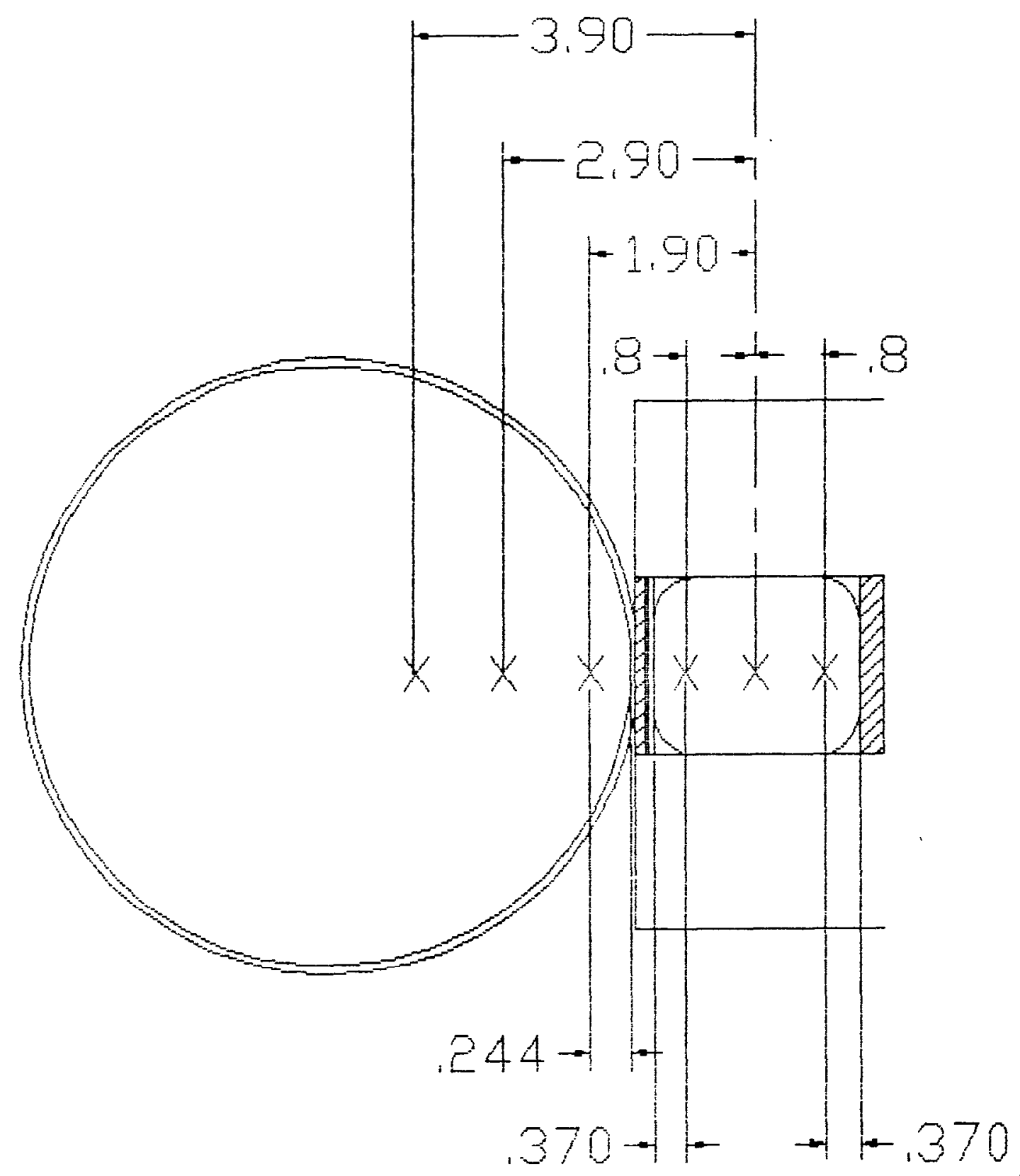

FIGURE 8: LDCATIDN DF MAGNETIC FIELD READINGS IN EXPERIMENT ARRANGEMENT 
FIELD (GAUSS )

(9) AD APERT GHAE TUBE

\begin{tabular}{llllll}
\hline-15.4 & -115.2 & -155.9 & 8673.0 & 8746.0 & 8867.6
\end{tabular}

(2) VIth AFERTURE TUBE

$-15$.

4.

3

2

1

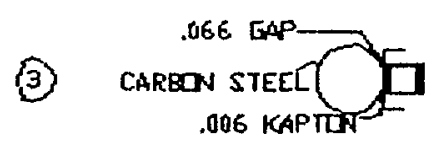

$\begin{array}{lll}-27.8 & -33.4 & -53.9\end{array}$

8800.3

8949.0

89B1.5

066 GAP

(1)

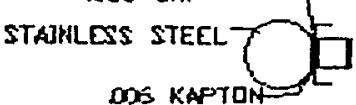

$-36.7$

$-47.8$

$-139.0$

B7E 4.9

$8 B 62.5$

9039.0

(5)

.066 GAF

DET MLAR

.00E K.APTOM

$-33$.

$-34.6$

$-38.9$

B855.9

BBS7.0

E) 92.0

(6)

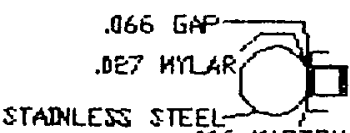

$-61$.

$-98.6$

$-130.9 \quad 8969.2$

8797.2

8772.6

(6)<smiles>C[R16](C)(C)[N+](=O)[O-]</smiles>

$-1540$

$-3690$

$-1007.1 \quad 7571.9$

7239.4

7549.1

(i) DEG GAF 2 C STARKESS STEE

$-87.9$

$-302.6$

$-985.6$

7368.7

7581.0

8095.2

DEE DOE KAFTON

(8)

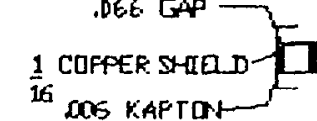

0

$-84.5$

$-93.3$

9010.2

8785.0

8957.2

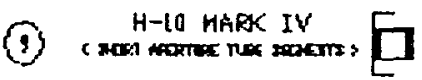

$-28$

8.7

$-39.5$

$-63.9$

9004.4

9040.5

9095.0

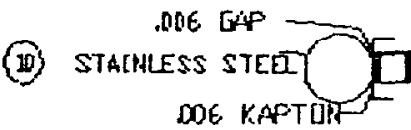

$-28$

$-44$

$-89.6$

8800.0

8968.3

6856.

(i) CaRban STEE

$-23$

(E) ampacis

$-32$

$-54.0$

$-115.2$

8737.4

8619.3

8737.4

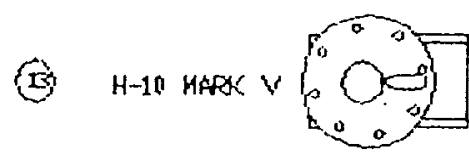

$\begin{array}{llll}-99.91 & -197.07 & -627.83 & 7310.4\end{array}$

7565.4

Q1.23.0 
MAGNETIC FIELD

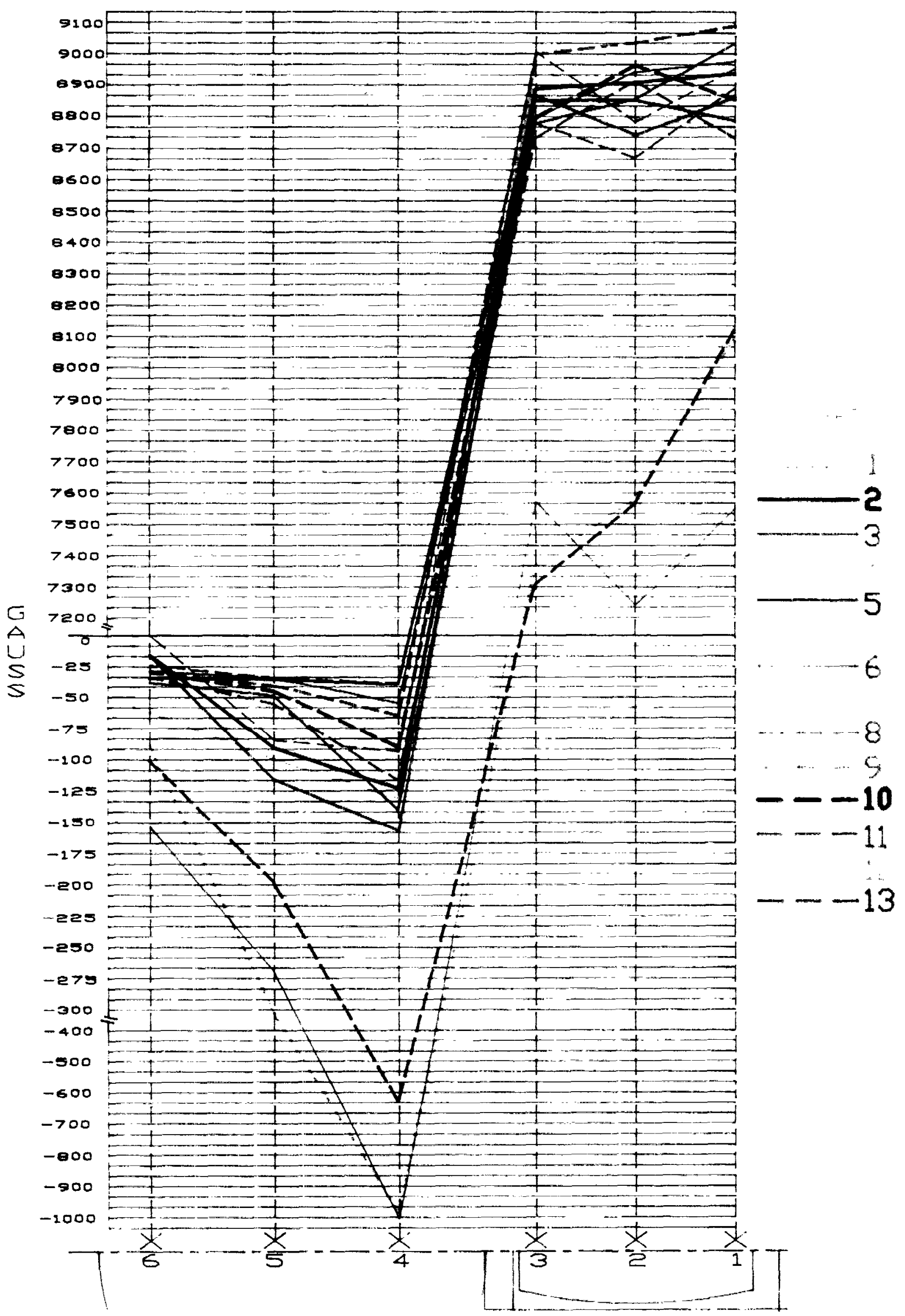

FIG : 10 
RESPDNSE TIME (MICROSECONDS )

\begin{tabular}{lll|ll}
6 & 5 & 4 & 3 & 2
\end{tabular}

(1) NO AFETURE TUAR

(2) VITH AFERTLRE TUYE

(3) CARHON STEETCD

(4)<smiles>CC(C)(C)[Mg][Mg][Mg][Mg]</smiles>

(5)

DSE. GAP

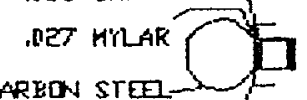

DOS KAPTOK

(3)

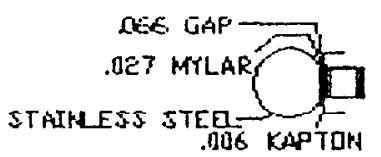

E)

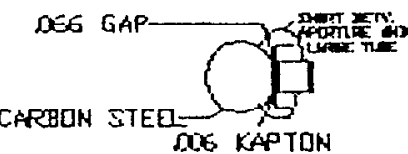

(5)

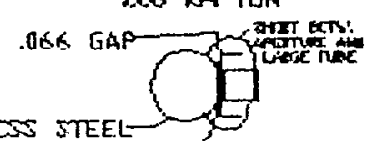

COS KAFTON

(B) . 656 GAF STA]HLES JTEEL

49

58

55

29

111

127

210

42

(10) STAMHLES SIEETC .006 GAF

(11) CAREOH STEEL

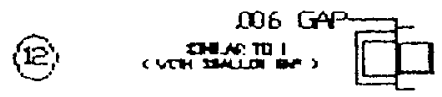

(1) H-10 NARK V

33

39

67.5
44

48

33

40

54

40

36

30

49

58

25

21

65

69

81

91

152

145

117

63

60

30

44

30

30

22

29

29

37
44
51

36

35

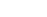

35

22

61

48

22

58

2E

85

$: 24$

177 


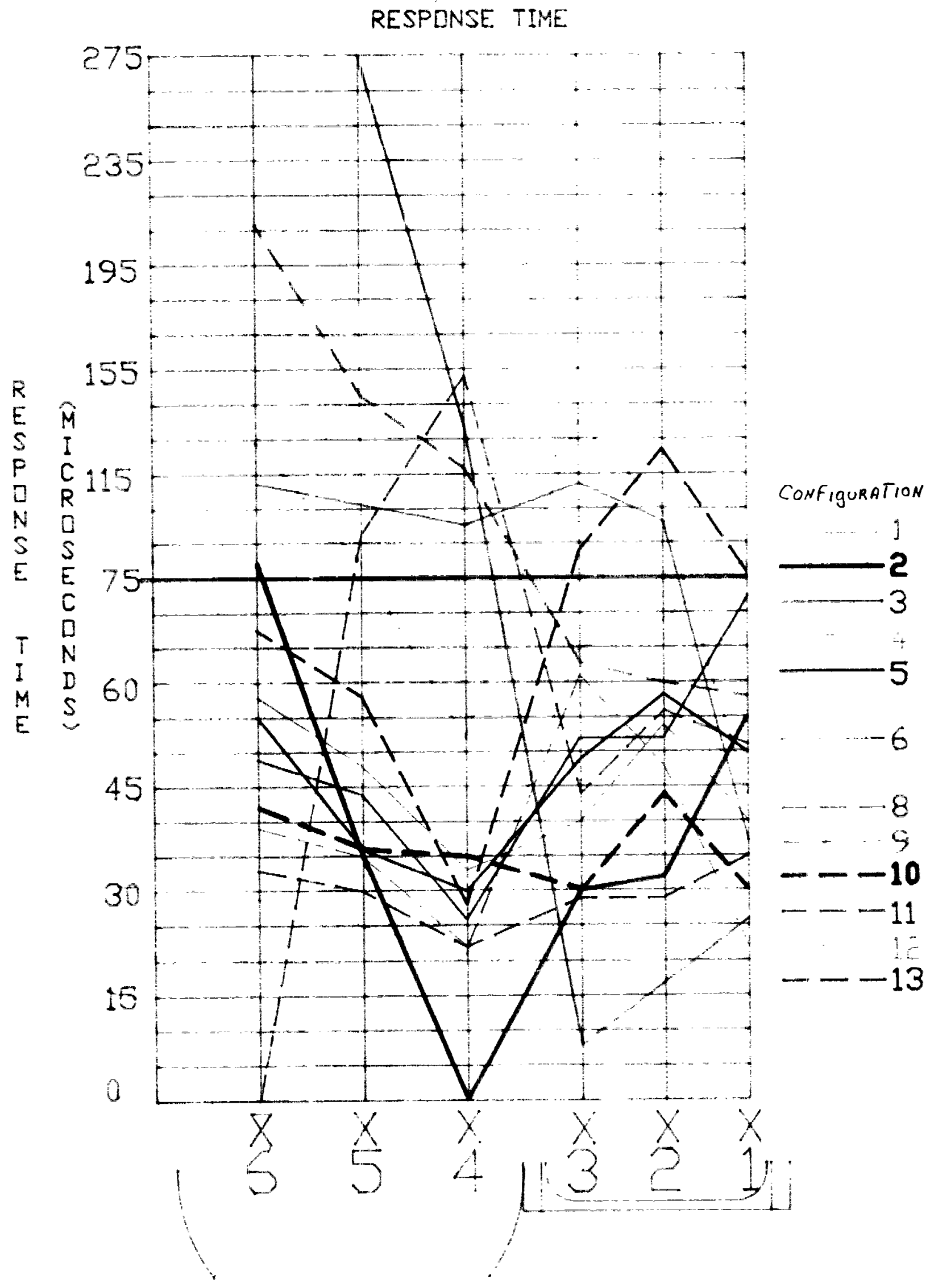

FIG. 12 